\title{
OSCILLATORY PORE PRESSURE AND LIQUEFACTION IN SEABED INDUCED BY OCEAN WAVES
}

\author{
KoukI ZeNi) and Hiroyuki Yamazaki ${ }^{\mathrm{ii}}$
}

\begin{abstract}
The oscillatory pore pressure excited in porous seabed by ocean waves is theoretically and experimentally examined in the context of the wave-induced liquefaction. A govering equation on the oscillatory pore pressure is presented and verified with the model tests. The comparisons of the finite difference solutions with the measurement of the oscillatory pore pressure have shown a good agreement. The governing equation is also adopted to estimate the liquefaction potential of the model seabed and its applicability is confirmed. It is shown that the waveinduced liquefaction is a kind of quick sand caused by the upward seepage force induced repeatedly in the seabed by ocean waves.
\end{abstract}

Key words: liquefaction, model test, ocean soil, pore pressure, sand, seepage, water pressure, wave propagation (IGC: E 7/E 8)

\section{INTRODUCTION}

The interaction between propagating ocean waves and seabed has received an extensive attention in the field of offshore engineering. The wave-induced liquefaction in porous seabed is one of the significant research subjects since the liquefaction, if it happens, may cause severe damage of offshore structures.

Yamamoto (1977), Madsen (1978), Finn et al. (1983) and Okusa (1985) analyzed the waveassociated stress in the porous seabed, on the basis of Biot's poro-elastic theory, by coupling the pore pressure with the stress or strain in the seabed. May and Foda (1981) and Mynett and Mei (1982) applied Biot's type equation to the interaction problems among waves, offshore structures and seabeds. Nago (1981) derived the same governing equation as those by Yamamoto (1977) and Madsen (1978) and interpreted the liquefaction phenomena in sand deposits reproduced by laboratory experiments. Biot's type of coupled equations are more attractive than others presented by Sleath (1970), Liu et al. (1979), Moshagen and Tørum (1975) and Inoue (1975), in a sense that they give not only the oscillatory pore pressure but also the stress in the seabed.

In these previous papers, however, the waveinduced liquefaction in the porous seabed is not clearly addressed in the geotechnical sense of the word. Namely, even if the tensile

i) Chief, Soil Dynamics Laboratory, Geotechnical Engineering Division, Port and Harbour Research Institute, Ministry of Transport, Nagase 3-1-1, Yokosuka, 239.

ii) Member, ditto.

Manuscript was received for review on July 18, 1989.

Written discussion on this paper should be submitted before July 1, 1991, to the Japanese Society of Soil Mechanics and Foundation Engineering, Sugayama Bldg. 4F, Kanda Awaji-cho 2-23, Chiyoda-ku, Tokyo 101, Japan. Upon request the closing date may be extended one month. 
stress in the seabed is given by the elastic analysis, it does not necessarily mean the occurrence of the liquefaction unless the excess pore pressure is clarified. Zen and Yamazaki (1990) presented an liquefaction criterion in which the dominant factors on the liquefaction are the wave-associated bottom pressure, the oscillatory pore pressure in the seabed and the vertical effective stress at calm. When the wave-associated bottom pressure and the vertical effective stress at calm are given, the only factor to be known is the oscillatory pore pressure in the seabed. Therefore, in this paper, the characteristics of the oscillatory pore pressures are investigated in detail in the context of the wave-induced liquefaction in the porous seabed.

\section{LIQUEFACTION CRITERIA}

When ocean waves propagate over the seabed, they induce the oscillatory excess pore pressures and effective stress changes in the seabed. The effective stress, $\sigma^{\prime}{ }_{v}$, under one dimensional plane strain conditions, is generally expressed by the following equation (Zen and Yamazaki, 1990):

$$
\sigma^{\prime}{ }_{v}=\sigma^{\prime}{ }_{v 0}+\left(p_{b}-p_{m}\right)
$$

where, $\sigma_{v_{0}}^{\prime}$; the vertical effective stress at calm, $p_{b}$; the wave-associated pressure at the surface of the seabed and $p_{m}$; the oscillatory pore pressure induced in the seabed. Then, the oscillatory excess pore pressure, $u_{e}$, is defined by :

$$
u_{e}=-\left(p_{b}-p_{m}\right)
$$

The liquefaction criterion of the porous seabed is derived from Eq. (1):

$$
\sigma^{\prime}{ }_{v 0} \leqq-\left(p_{b}-p_{m}\right)
$$

Therefore, if the $\sigma^{\prime}{ }_{v 0}, p_{b}$ and $p_{m}$ are kown, the liquefaction potential can be easily evaluated. As the $\sigma^{\prime}{ }_{v 0}$ is obtained from the submerged unit weight of deposits and the $p_{b}$ is estimated approximately by the linear wave theory, the only factor to be known is the oscillatory pore pressure, $p_{m}$.

\section{OSCILLATORY PORE PRESSURE}

Governing Equation to Irregular Waves

The propagation of ocean waves exerts the differential pressures on the surface of the seabed. When the wave length is large enough compared with the thickness of permeable seabed, it may be assumed that the waveassociated pressures distribute uniformly on the surface of the seabed. Then, the oscillation of pressures and the flow of pore water are treated under one dimentional conditions.

Concidering a soil element at depth, $z$, in the seabed and assuming the flow of pore water in the soil element is governed by the steady state form of Darcy's law, Eq. (4) is derived from the conservation of mass of pore water:

$$
\frac{k}{\gamma_{w}} \frac{\partial^{2 P_{m}}}{\partial z^{2}}=-m_{v} \frac{\partial \sigma^{\prime}{ }_{v}}{\partial t}+n m_{w} \frac{\partial^{P} m}{\partial t}
$$

where, $k$; the coefficient of permeability, $m_{v}$; the coefficient of volume compressibility, $n$; the porosity, $m_{w}$; the compressibility of pore water including air, $\gamma_{w}$; the unit weight of pore water and $t$; time. The $k$ and $m_{v}$ are assumed constant irrespective of time and space. As the effective vertical stress is expressed by Eq. (1) and $\partial \sigma^{\prime}{ }_{v_{0}} / \partial t$ is equal to 0 , we obtain,

$$
\frac{\partial \sigma^{\prime} v}{\partial t}=\frac{\partial\left(p_{b}-p_{m}\right)}{\partial t}
$$

which may be introduced into Eq. (4) to yield:

$$
\frac{k}{\gamma w m_{v}} \frac{\partial^{2} p_{m}}{\partial z^{2}}=\left(1+\frac{n m_{w}}{m_{v}}\right) \frac{\partial p_{m}}{\partial t}-\frac{\partial p_{b}}{\partial t}
$$

Replacing,

$$
\begin{aligned}
& C_{v}=\frac{k}{\gamma_{w} m_{v}} \\
& \alpha=1+\frac{n m_{w}}{m_{v}}
\end{aligned}
$$

Eq. (6) may be written in the form:

$$
C_{v} \frac{\partial^{2} p_{m}}{\partial z^{2}}=\alpha \frac{\partial p_{m}}{\partial t}-\frac{\partial p_{b}}{\partial t}
$$

Eq. (9) represents the governing equation on the oscillatory pore pressure in the seabed, applicable to any complex wave conditions such as random waves in real ocean.

As the oscillatory pore pressure is equal to the wave-associated pressure at the surface of the seabed, the boundary codition is written: 


$$
p_{m}=p_{b} \quad \text { at } \quad z=0
$$

If the porous seabed is of finite thickness, $l$, and the underlying soil is assumed impermeable, no water flow normal to the horizontal boundary comes rise to. Thus, we obtain:

$$
\frac{\partial p_{m}}{\partial z}=0 \quad \text { at } \quad z=1
$$

Initial condition is written as:

$$
p_{m}=0 \quad \text { at } \quad t=0
$$

It is noted that the $p_{m}$ does not mean the 'excess' pore pressure but denotes the oscillatory nature of pore pressure. The governing equation on the excess pore pressure is derived from Eq. (9) by using Eq. (2) :

$$
C_{v} \frac{\partial^{2} u_{e}}{\partial z^{2}}=\alpha \frac{\partial u_{e}}{\partial t}+(\alpha-1) \frac{\partial p_{b}}{\partial t}
$$

When the compressibility of pore water is negligible, say the coefficient, $\alpha$, is equal to 1.0, Eq. (13) becomes identical with the consolidation equation.

\section{Governing Equation to Linear Waves}

When a small amplitude wave is assumed, the wave-associated pressure on the surface of the seabed, $p b$, is expressed by the linear wave theory:

$$
\begin{gathered}
p_{b}=p_{0} \sin \left(\frac{2 \pi t}{T}\right) \\
p_{0}=\frac{\gamma_{w} H}{2} \frac{1}{\cosh (2 \pi h / L)}
\end{gathered}
$$

where, $H$; the wave height, $T$; the wave period, $L$; the wave length and $h$; the water depth. Eq. (9) is rewritten by replacing,

$$
\begin{aligned}
& \bar{P}=\frac{p_{m}}{p_{0}} \\
& \bar{Z}=\frac{z}{l} \\
& \bar{T}=\frac{t}{T} \\
& C=\frac{C_{v} T}{l^{2}}
\end{aligned}
$$

in the form:

$$
C \frac{\partial^{2} \bar{P}}{\partial \bar{Z}^{2}}=\alpha \frac{\partial \bar{P}}{\partial \bar{T}}+2 \pi \cos (2 \pi \bar{T})
$$

The boundary conditions are:

$$
\bar{P}=\sin (2 \pi \bar{T}) \quad \text { at } \quad \bar{Z}=0
$$

$$
\frac{\partial \bar{P}}{\partial \bar{Z}}=0 \quad \text { at } \quad \bar{Z}=1
$$

The initial condition is:

$$
\bar{P}=0 \quad \text { at } \bar{T}=0
$$

With the same manner, Eq. (13) is expressed in terms of the non-dimentional excess pore pressure,

$\bar{U}:$

$$
C \frac{\partial^{2} \bar{U}}{\partial \bar{Z}^{2}}=\alpha \frac{\partial \bar{U}}{\partial \bar{T}}+2 \pi(\alpha-1) \cos (2 \pi \bar{T})
$$

where,

$$
\bar{U}=\frac{u_{e}}{p_{0}}
$$

Coefficient: $C$

The meanings of the coefficient, $C$, can be found by setting the coefficient, $\alpha$, is equal to 1.0 in Eq. (24). Since Eq. (24) becomes identical with the consolidation equation, the $C$ defined by Eq. (19) is considered to represent the drainage effect of the excess pore pressure. As the coefficient of consolidation, $C_{v}$, and the wave period, $T$, become larger and as the thickness of permeable layer, $l$, becomes smaller, the excess pore pressure will dissipate more quickly from the permeable seabed. In this sense, the non-dimensional coefficient, $C$, is referred to the coefficient of drainage, hereafter. The coefficient of drainage has a similar form to the time factor in which the time is replaced by the wave period.

Coefficient: $\alpha$

Provided that the seabed is under undrained conditions, the left term in Eq. (9) is omitted. Then, Eq. (9) is rewritten as:

$$
\frac{1}{\alpha}=\frac{\partial p_{m} / \partial t}{\partial p_{b} / \partial t}
$$

Since the right term in Eq. (26) denotes the increase rate of the oscillatory pore pressure to the wave-associated bottom pressure, the $(1 / \alpha)$ appears equivalent to the Skempton's $\mathrm{B}$-value. It is, however, true only under the steady states of the pressures of $p_{b}$ and $p_{m}$. Under the transient states of the pressures, the $(1 / \alpha)$ is, in general, a function of time, closely related to the compressibility of pore water.

The compressibility of pore water is affected 
by the amount of the dissolved air in water and the attached air to the soil particles. It is known that the effect of such air is represented by the degree of saturation, $S_{r}$ and the pore pressure by means of absolute value, $p_{m g}$. The $p_{m g}$ is represented by the sum of the hydrostatic pressure and the wave-associated dynamic pressure. Okusa (1985) presented the compressibility of pore water by the following equation:

$$
m_{w}=m_{w_{0}} S_{r}+\frac{1-S_{r}}{p_{m g}}
$$

where, $m_{w_{0}}$; the compressibility of water at fully saturated state. Introducing Eq. (27) into Eq. (8), we obtain:

$$
\alpha=1+\frac{n}{m_{v}}\left(m_{w_{0}} S_{r}+\frac{1-S_{r}}{p_{m g}}\right)
$$

The $\alpha$ is function of time because the $p_{m g}$ varies according to the wave-associated bottom pressure. It is, however, shown by Inoue (1975) that the rapid variation of the dynamic component to the $p_{m g}$, usually met during storm waves, affects the compressibility of pore water very little.

If the degree of saturation is equal to 1.0 and the compressibility of pore water, $m_{w_{0}}$, is small enough to be ignored, the $\alpha$ becomes equal to 1.0. Then, the wave-associated pressure on the surface of the seabed, $p_{b}$, is fully propagated into the seabed. Thus, the oscillatory pore pressure, $p_{m}$, becomes identical with the $p r$. This means that no excess pore pressure is excited in the seabed. Whereas, when the $S_{r}$ is less than 1.0, say the $\alpha$ is greater than 1.0, the $p_{b}$ is not completely propagated into the seabed and the $p_{m}$ will be less than $p_{b}$. Therefore, the $\alpha$ is considered a coefficient representing the propagation characteristics of the water pressure and is referred to the coefficient of propagation, hereafter.

\section{Finite Difference Solution}

In order to solve Eq. (20), the finite difference analysis is adopted. The differential meshes in space and time used in the computation are respectively $\Delta \bar{Z}=0.1$ and $\Delta \bar{T}=$ 0.001 . These mesh intervals are determined from the ones that give the stable and con-
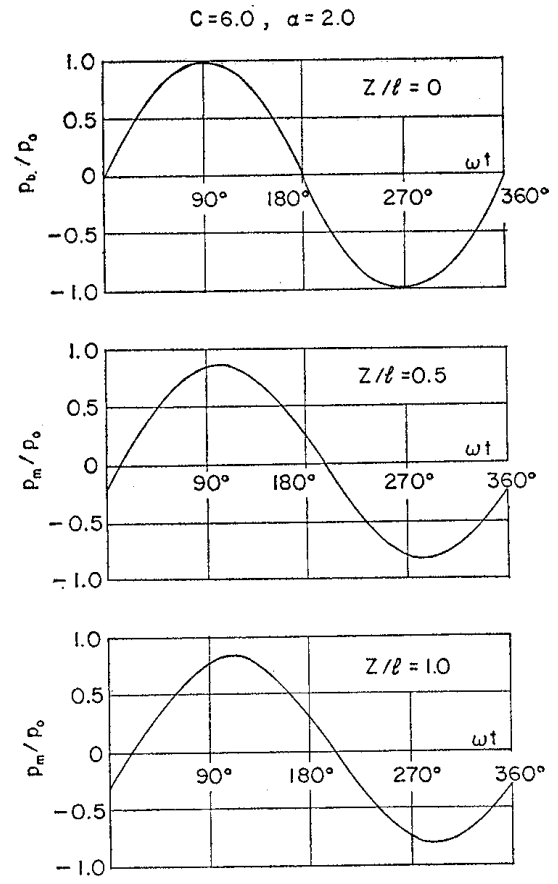

Fig. 1. Response of pore pressure

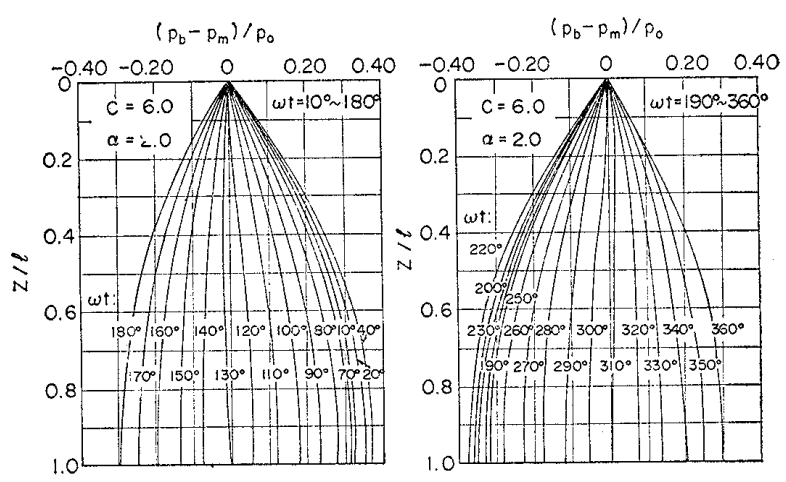

Fig. 2. Vertical effective stress change

vergent solutions. The computation is continued for more than 3 cycles of waves, until the steady state of the oscillatory pore pressures are obtained. An example of the solution is illustrated in Figs. 1 and 2 . It is clearly shown in Fig. 1 that the wave-associated pressure, po, propagates into the seabed with damping and phase lag. The changes in the effective stresses, $\left(p_{b}-p_{m}\right)$, are presented in Fig. 2, in which the $\left(p_{b}-p_{m}\right)$ is normalized by the amplitude of the wave-associated pressure, $p_{0}$. In Fig. 2 , the vertical effective stresses oscillate continuously on both negative and positive sides even in one period of the wave loading. According to the liquefaction criterion, it is understood that the liquefact- 
ion will take place where the wave-associated stresses exceed the vertical effective stresses at calm.

\section{Influential Factors on Oscillatory Pore Pres. sure}

Referring to Eqs. (6), (14) and (15), the influential factors on the oscillatory pore pressure, $p_{m}$, are expressed by a function, $F$ :

$$
\begin{gathered}
p_{m}=F\left(H, L, T, m_{v}, k, n, \gamma_{w}, m_{w},\right. \\
\left.h, z, l, t, S_{r}, N_{c}\right)
\end{gathered}
$$

Among these factors, the $H, L, T$ and $N_{c}$ are the factors depending on the wave characteristics. The $m_{v}$ and $n$ are related to the soil properties, and the $\gamma_{w}$ and $m_{w}$ depend on the properties of pore water. The $h, l$ and $z$ are the geometrical factors. The $k$ and $S_{r}$ are related to the properties both of soils and pore water. Although the number of waves, $N_{c}$, is not included in Eq. (6), it is an important factor to be considered.

When a small amplitude wave is assumed and the non-dimensional pressure ratio, $\bar{P}$, is introduced, Eq. (29) can be expressed simply by the following function, $G$ :

$$
\bar{P}=G\left(\bar{T}, \bar{Z}, C, \alpha, N_{c}\right)
$$

When the $\bar{T}$ and $\bar{Z}$ are given, the influential factors on the $\bar{P}$ are represented by the $C, \alpha$ and $N_{c}$.

\section{EXPERIMENTS}

Model tests were performed, under one dimensional wave loading conditions, with a newly developed apparatus shown in Fig. 3. The apparatus is made up of 1 ) a cylinder for constituting the model seabed, which is composed of sixteen cells, 2) a pneumatic sine loading unit to apply the hydro-static and dynamic pressures, 3) measuring sensors and 4) a recording system. The air-dried Toyoura sand, the physical properties of which were

Table 1. Physical properties

\begin{tabular}{lc|l}
\hline Specific gravity & $G_{s}$ & 2.674 \\
Maximum void ratio & $e_{\max }$ & 0.988 \\
Minimum void ratio & $e_{\min }$ & 0.615 \\
Mean grain size & $D 50(\mathrm{~mm})$ & 0.181 \\
Uniformity coefficient & $U_{c}$ & 1.79 \\
\hline
\end{tabular}

shown in Table 1, was poured into the cells in the process of the fabrication of the cylinder. The thickness of deposit is $1.90 \mathrm{~m}$ and the initial relative density is $50 \%$. The carbon dioxide gas was circulated before filling the water. The hydro-static pressure of $1.0 \mathrm{kgf} /$ $\mathrm{cm}^{2}\left(98 \mathrm{kN} / \mathrm{m}^{2}\right)$ was applied to the deposit. Then, sinusoidal wave forms of the dynamic pressures were repeated up to 500 cycles in each loading stage. The double amplitudes of the hydro-dynamic pressures were between $0.197 \mathrm{kgf} / \mathrm{cm}^{2}\left(19.3 \mathrm{kN} / \mathrm{m}^{2}\right)$ and $0.818 \mathrm{kgf} / \mathrm{cm}^{2}$ $\left(80.2 \mathrm{kN} / \mathrm{m}^{2}\right)$. The wave periods wave between $3 \mathrm{~s}$ and $15 \mathrm{~s}$. The applied wave loading conditions are tabulated in Table 2. The oscillatory pore pressures were measured at the depth shown by P 1, P 3, P 5, P 7, P 9, P 11, $\mathrm{P} 13$ and PL in Fig. 3. After the wave loading has been completed, the density of the deposit and the degree of saturation were measured by cutting out the deposit in each cell of the cylinder. More details of the experiments are presented elsewhere (Zen et al., 1987).

The permeability tests were performed using Toyoura sand for several kinds of the relative density. One dimensional cyclic compression tests were separately executed with a steel mould. The inner diameter and the height of

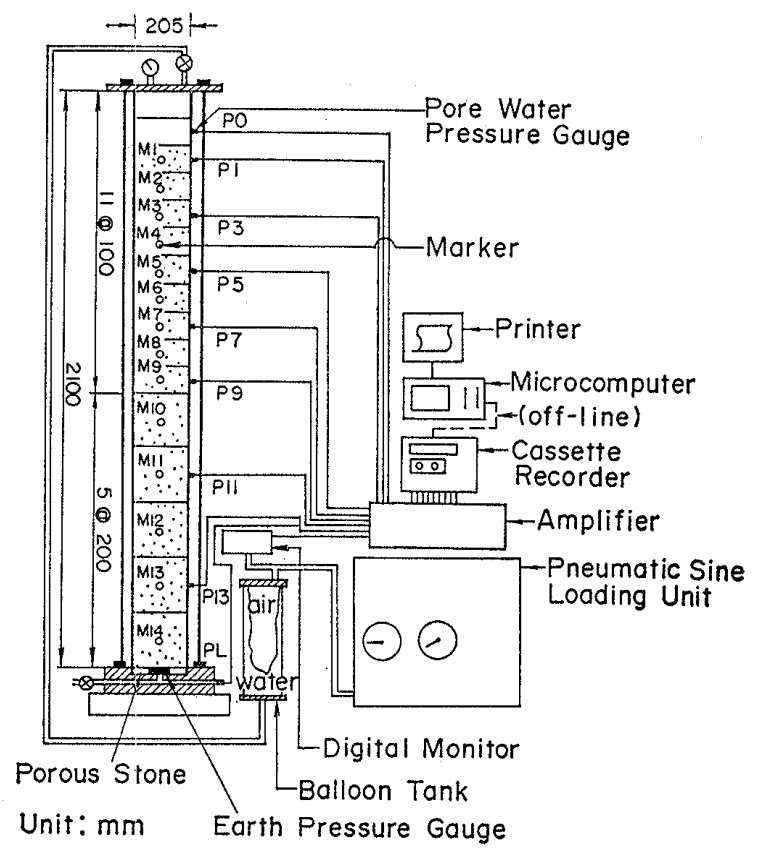

Fig. 3. Test apparatus 
Table 2. Test conditions

\begin{tabular}{|c|c|c|c|c|c|c|}
\hline $\begin{array}{l}\text { Test } \\
\text { No. }\end{array}$ & $\begin{array}{c}\text { Stage } \\
\text { No. }\end{array}$ & $\begin{array}{c}\text { Applied pressure } \\
2 \vec{p}_{0} \\
\left(\mathrm{kgf} / \mathrm{cm}^{2}\right)\end{array}$ & $\begin{array}{c}\text { Applied wave period } \\
\qquad \begin{array}{c}T \\
\text { (s) }\end{array}\end{array}$ & $\begin{array}{c}\text { Thickness } \\
\qquad \begin{array}{l}l \\
(\mathrm{~m})\end{array}\end{array}$ & $\begin{array}{c}\text { Relative density } \\
D_{r 0} \\
(\%)\end{array}$ & Remarks \\
\hline 1 & $\begin{array}{l}1 \\
2 \\
3 \\
4 \\
5 \\
6 \\
7 \\
\end{array}$ & $\begin{array}{l}0.197 \\
0.325 \\
0.473 \\
0.722 \\
0.555 \\
0.390 \\
0.243\end{array}$ & $\begin{array}{r}7 \\
9 \\
11 \\
13 \\
11 \\
9 \\
7 \\
\end{array}$ & 1.90 & 50 & - \\
\hline 2 & $\begin{array}{l}1 \\
2 \\
3 \\
4 \\
\end{array}$ & $\begin{array}{l}0.507 \\
0.509 \\
0.515 \\
0.497\end{array}$ & $\begin{array}{r}15 \\
11 \\
7 \\
3 \\
\end{array}$ & 1.90 & 50 & $2 \bar{p}_{0} \fallingdotseq$ constant \\
\hline & $\begin{array}{l}5 \\
6 \\
7 \\
8\end{array}$ & $\begin{array}{l}0.791 \\
0.793 \\
0.813 \\
0.818\end{array}$ & $\begin{array}{r}15 \\
13 \\
11 \\
9\end{array}$ & & & $2 \bar{p}_{0} \fallingdotseq$ constant \\
\hline 3 & $\begin{array}{l}1 \\
2 \\
3 \\
4 \\
5 \\
6 \\
7\end{array}$ & $\begin{array}{l}0.247 \\
0.439 \\
0.595 \\
0.756 \\
0.604 \\
0.443 \\
0.253 \\
\end{array}$ & $\begin{array}{l}7 \\
7 \\
7 \\
7 \\
7 \\
7 \\
7\end{array}$ & 1.90 & 50 & $T=$ constant \\
\hline 4 & $\begin{array}{l}1 \\
2 \\
3 \\
4 \\
5 \\
6 \\
7\end{array}$ & $\begin{array}{l}0.258 \\
0.445 \\
0.618 \\
0.804 \\
0.633 \\
0.446 \\
0.266\end{array}$ & $\begin{array}{r}7 \\
9 \\
11 \\
13 \\
11 \\
9 \\
7 \\
\end{array}$ & 1.90 & 50 & $q_{s}=0.0716 \mathrm{kgf} / \mathrm{cm}^{2}$ \\
\hline
\end{tabular}

1) the number of waves, $N_{c}$, in each stage; 500 cycles.

2) $q_{s}$; overburden pressure.

3) $1 \mathrm{kgf} / \mathrm{cm}^{2}=98 \mathrm{kN} / \mathrm{m}^{2}$.

the mould are $305 \mathrm{~mm}$ and $350 \mathrm{~mm}$, respectively. The loading and unloading and reloading were repeated up to 5 cycles by applying the weight step by step. The vertical settlements were measured at each loading step. The coefficient of volume compressibility was estimated from the vertical stress and strain relationships. The coefficient of permeability and the coefficient of volume compressibility were used to calculate the coefficient of consolidation.

The coefficient of propagation was measured with a conventional cyclic triaxial test apparatus. The specimen, the diameter and the height of which were respectively $50 \mathrm{~mm}$ and $125 \mathrm{~mm}$, was constructed in the cell. The degree of saturation of specimens was roughly controlled in the process of the construction of specimens. The specimens were isotro pically consolidated with the cell pressures between $1.5 \mathrm{kgf} / \mathrm{cm}^{2}\left(147 \mathrm{kN} / \mathrm{m}^{2}\right)$ and 2.5 $\mathrm{kgf} / \mathrm{cm}^{2}\left(245 \mathrm{kN} / \mathrm{m}^{2}\right)$ under the back pressure of $1.0 \mathrm{kgf} / \mathrm{cm}^{2}\left(98 \mathrm{kN} / \mathrm{m}^{2}\right)$. The sinusoidal forms of the cyclic cell pressures whose amplitudes were between $0.1 \mathrm{kgf} / \mathrm{cm}^{2}\left(9.8 \mathrm{kN} / \mathrm{m}^{2}\right)$ and $0.3 \mathrm{kgf} / \mathrm{cm}^{2}\left(29.4 \mathrm{kN} / \mathrm{m}^{2}\right)$ were repeated up to 500 cycles in maximum. The responses of the pore pressures in the specimen as well as the cell pressures were recorded. The Bvalue was measured before and after the cyclic loading. The exact value of the degree of saturation was measured im mediately after the tests. The coefficient of propagation was evaluated by using Eqs. (26) and (28). 


\section{TEST RESULTS}

\section{Wave Characteristics affecting Oscillatory} Pore Pressure

a) Wave Height, Wave Length and Water Depth

Fig. 4 shows the relationships between the amplitude of wave-associated bottom pressure, $p_{0}$, and the pressure ratio, $p_{m} / p_{0}$, at the nondimensional depths, $z / l=0.13$ and 0.84 . It is found in Fig. 4 that the pressure ratio is

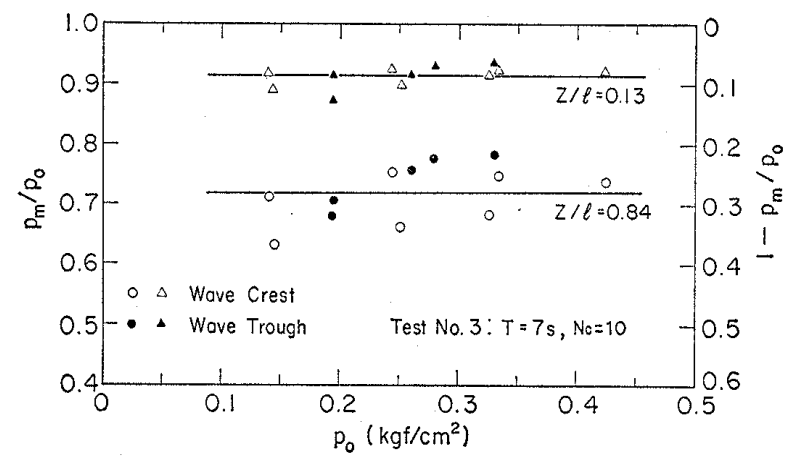

Fig. 4. Pressure ratio and wave-associated bottom pressure $\left(1 \mathrm{kgf} / \mathrm{cm}^{2}=98 \mathrm{kN} / \mathrm{m}^{2}\right)$

constant irrespective of the $p_{0}$. As the $p_{0}$ is a function of the wave height, $H$, the wave length, $L$, and the water depth, $h$, as shown in Eq. (15), the oscillatory pore pressure in terms of the non-dimensional pressure ratio, $p_{m} / p_{0}$, is considered independent of the $H, L$ and $h$.

\section{b) Wave Period}

Fig. 5 shows the pressure ratio and the wave period, $T$, at the non-dimensional depth, $z / l$ $=0.45$. The ranges of the existing data by other investigators which are collected and presented by Zen and Yamazaki (1990), are also drawn by the dotted lines in Fig. 5 . The

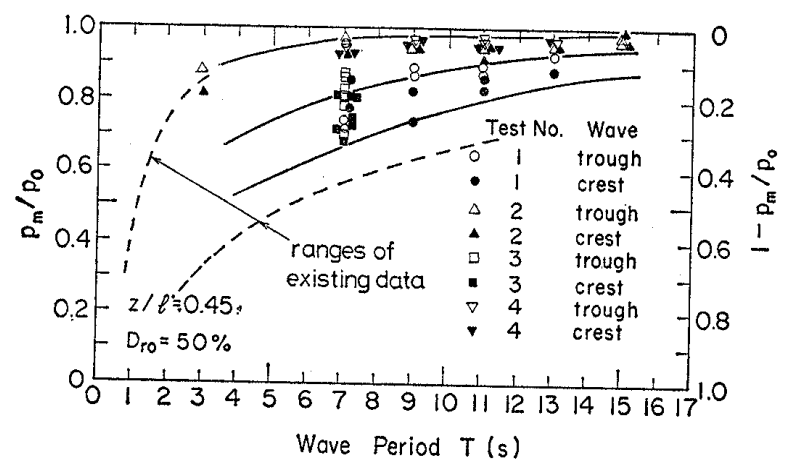

Fig. 5. Pressure ratio and wave period pressure ratio decreases from about 1.0 to $0.2 \sim$ 0.3 as the wave period becomes smaller. The wave period is considered one of the dominant factors to the oscillatory pore pressure in the seabed. Assuming the linear waves, this effect can be taken into account by the coefficient of drainage defined by Eq. (19).

c) Number of Waves

The oscillatory pore pressures may vary depending on the number of waves. As this effect is not included in the governing equation shown in Eqs. (9) and (20), it was experimentally examined. Figs. 6 indicates the effect of the number of waves, $N_{c}$, on the pressure ratio, $p_{m} / p_{0}$. As can be seen in Fig. 6 , quite little difference of the pressure ratio at each number of waves is observed. Fig. 7 shows the variance of the pressure ratio between at arbitrary number of waves, $N_{c}$, and at 10 cycles, $\left(p_{m} / p_{0}\right)_{N c} /\left(p_{m} / p_{0}\right)_{N c 10}$, against the nondimensional cycle, $N_{c} / N_{c 10}$. The $N_{c 10}$ in Fig. 7 denotes the number of waves, 10 cycles. It is shown that the $\left(p_{m} / p_{0}\right)_{N c} /\left(p_{m} / p_{0}\right)_{N c 10}$ lies within $5 \%$ of a narrow range, regardless of the non-dimensional cycles. Therefore,

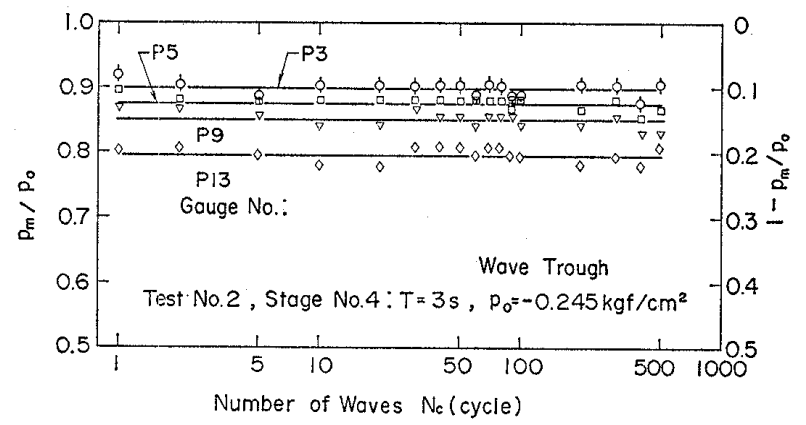

Fig. 6. Pressure ratio and number of waves (1. $\mathrm{kgf} / \mathrm{cm}^{2}=98 \mathrm{kN} / \mathrm{m}^{2}$ )

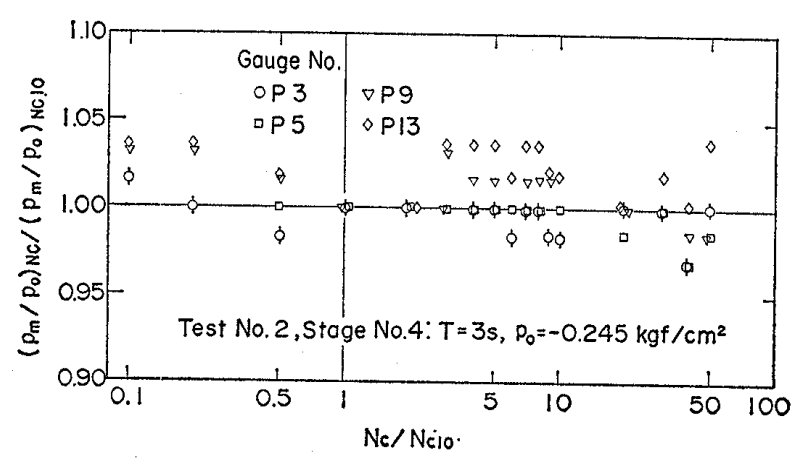

Fig. 7. Change in pressure ratio

$\left(1 \mathrm{kgf} / \mathrm{cm}^{2}=98 \mathrm{kN} / \mathrm{m}^{2}\right)$ 


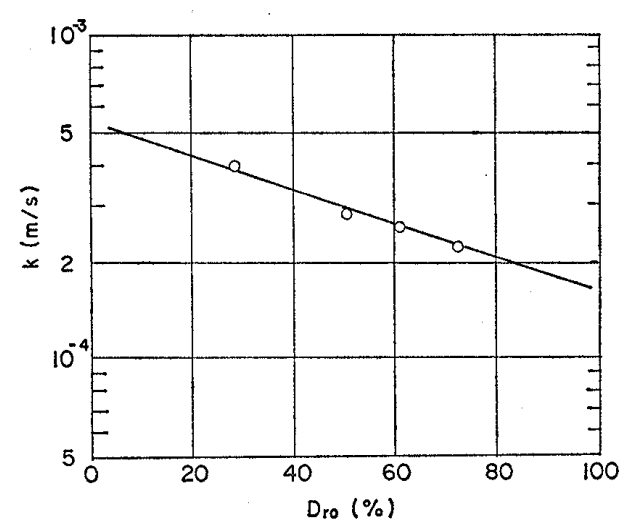

Fig. 8. Coefficient of permeability

the effect of the number of waves on the oscillatory pore pressures can be considered so small to be ignored.

\section{Coefficient of Drainage}

The coefficient of drainage, $C$, is defined by the coefficient of consolidation, $C v$, the wave period, $T$, and the thickness of permeable layer, $l$. Since the $T$ and $l$ are dependent of the wave characteristics and the seabed profile, respectively, the $C_{v}$ is examined experimentally in the laboratory. Fig. 8 shows the relationship between the coefficient of permeability, $k$, and the initial relative density,

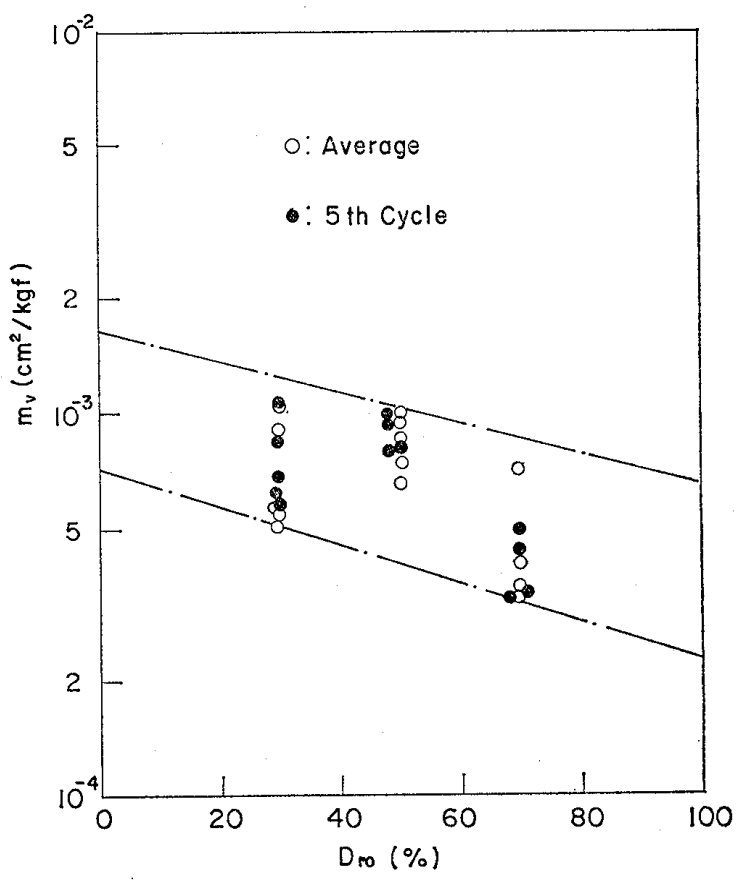

Fig. 9. Coefficient of volume compressibility $\left(1 \mathrm{kgf} / \mathrm{cm}^{2}=98 \mathrm{kN} / \mathrm{m}^{2}\right)$

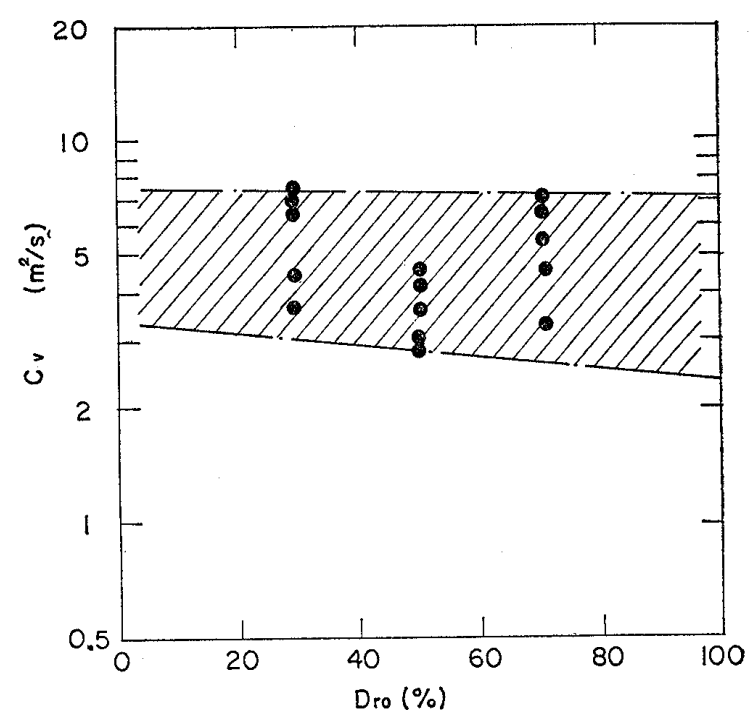

Fig. 10. Coeficient of consolidation

$D_{r 0}$. The $k$ de- creases linearly on the semi-log scale in accordance with the increase of the $D_{r 0}$. Fig. 9 is the coefficient of volume compressibility, $m_{v}$, calculated from the stress-strain relationships measured from more than four specimens with the same relative density. The plots corresponding to the rebound process are illustrated in Fig. 9 because the $m_{v}$ in such process is considered more dominant to the liquefaction. It is found from Fig. 9 that the $m_{v}$ as well as the $k$ shown in Fig. 8 tends to decrease as the $D_{r_{0}}$ increases. The open and solid circles in Fig. 9 denote the average value of the $m_{v}$ in 5 cycles and the value at the 5 th cycle, respectively. The differences of these plots seem rather small, so that the average value of the $m_{v}$ in 5 cycles is adopted to estimate the $C_{v}$. Fig. 10 shows the relationships be tween the $C_{v}$ and the $D_{r 0}$ calculated from the $k$ and the $m_{v}$. The plots in Fig. 10 appear to be slightly dependent of the relative density. The $C_{v}$ is, however, regarded approximately constant without reference to the relative density in this study. This assumption will be acceptable, when it is taken into account that the change of the relative density of sand deposits is considerably little unless the liquefaction and successive densification occur in deposits (Zen and Yamazaki, 1990).

\section{Coefficient of Propagation}




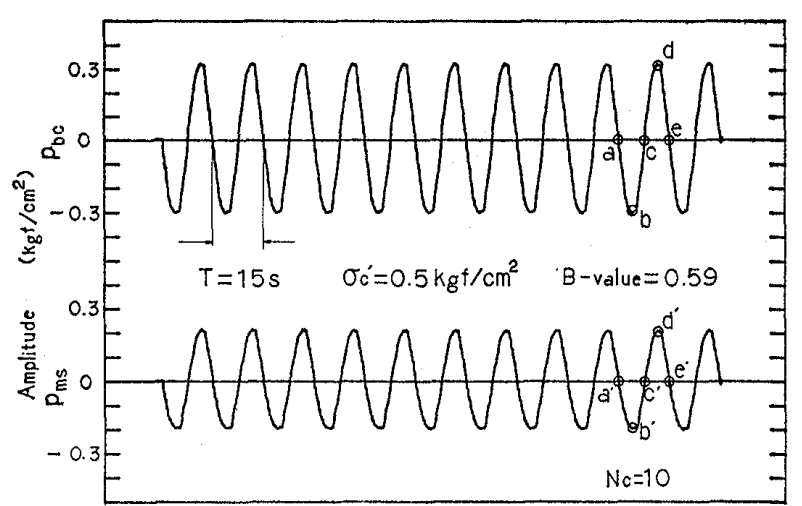

Fig. 11. An example of pressure response $\left(1 \mathrm{kgf} / \mathrm{m}^{2}=98 \mathrm{kN} / \mathrm{m}^{2}\right)$

The coefficient of propagation, $\alpha$, is expressed by Eq. (26). Thus, if the pore pressure responses, $\partial p_{m} / \partial t$, to the applied pressure increases, $\partial p_{b} / \partial t$, is measured under undrained conditions, the $\alpha$ is easily determined. Fig. 11 is an example of the pressure responses measured with a conventional cyclic triaxial test apparatus. The $p_{b c}$ and the $p_{m s}$ in Fig. 11 indicate the isotropically applied cyclic cell pressure and the oscillatory pore pressure in the specimen, respectively. It is found from 11 that the $p_{m}$ is less than the $p_{b c}$. This suggests that the $\alpha$ will become more than 1.0. So, the $\alpha$ is calculated with such observed data as shown in Fig. 11 by applying Eq. (26). The $\partial p_{m} / \partial t$ and the $\partial p_{0} / \partial t$ are obtained from the inclinations of lines like as $a b$, and $a^{\prime} b^{\prime}, b c$ and $b^{\prime} c^{\prime}$ in Fig. 11 and the average values of the fours are plotted in Fig. 12 in relation to the degree of saturation, $S_{r}$.

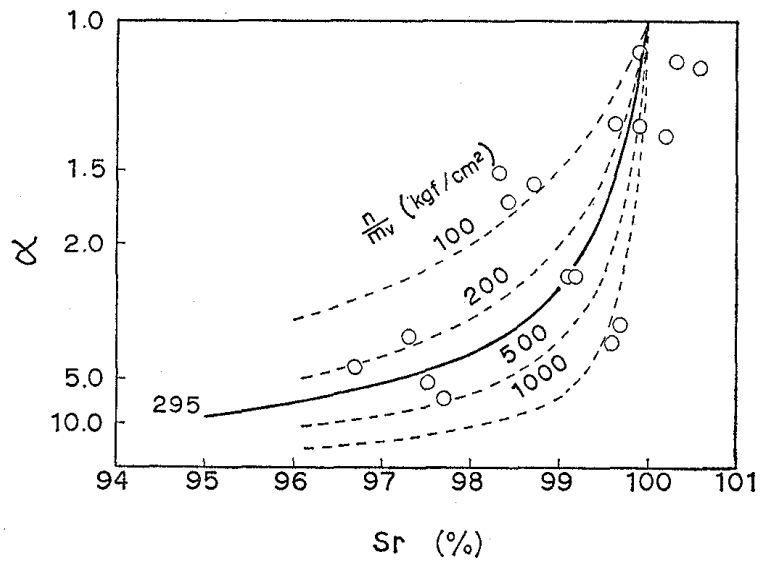

Fig. 12. Coefficient of propagation and degree of saturation $\left(1 \mathrm{~kg} / \mathrm{cm}^{2}=98 \mathrm{kN} / \mathrm{m}^{2}\right)$
The $S_{r}$ is measured immediately after the test. The plots which correspond to the number of waves, 10 cycles, are conveniently drawn in Fig. 12, since little effect of the number of waves on the $\alpha$ is observed. In Fig. 12, the $\alpha$ increases drastically even by a small amount of the reduction of the $S_{r}$. It should be noted that the $\alpha$. is very sensitive to the $S_{r}$

The solid line indicates the relationship between the $\alpha$ and the $S_{r}$ drawn by the method of least squares to the open circles, in which Eq. (28) is adopted omitting the $m_{w_{0}}$, and the $2.0 \mathrm{kgf} / \mathrm{cm}^{2}\left(196 \mathrm{kN} / \mathrm{m}^{2}\right)$ of the hydro-static cell pressure is used for the $p_{m g}$. The $n / m_{v}$ of $295 \mathrm{kgf} / \mathrm{cm}^{2}\left(28.9 \mathrm{kN} / \mathrm{m}^{2}\right)$ is obtained for the solid line. The dotted lines in Fig. 12 are drawn from Eq. (28) for various assumed values of the $n / m_{v}$. As the values of the $n / m_{v}$ separately measured with the one dimensional loading-unloading test are between $252 \mathrm{kgf} / \mathrm{cm}^{2}\left(24.7 \mathrm{MN} / \mathrm{m}^{2}\right)$ and 312 $\mathrm{kgf} / \mathrm{cm}^{2}\left(30.6 \mathrm{MN} / \mathrm{m}^{2}\right)$ for the compression process, and between $493 \mathrm{kgf} / \mathrm{cm}^{2}$ (48.3 MN/ $\left.\mathrm{m}^{2}\right)$ and $722 \mathrm{kgf} / \mathrm{cm}^{2}\left(70.8 \mathrm{MN} / \mathrm{m}^{2}\right)$ for the rebound process, the $n / m_{v}$ estimated from the solid line is in between the two. Taking account of the scatter of the data, the relationship estimated from Eq. (28) may be considered to represent the measured $\alpha$.

Fig. 13 is the $\alpha$ plotted against the relative density, $D_{r 0}$. The $\alpha$ is measured in the cell of the cyclic triaxial test apparatus. As can be seen from Fig. 13, the effect of the $D_{r 0}$ on the $a$ is quite little, compared with that of $\mathrm{B}$-value.

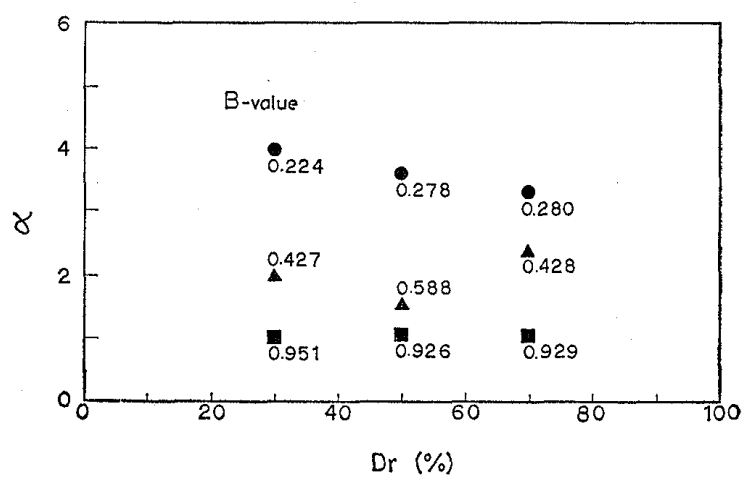

Fig. 13. Coefficient of propagation and relative density 
$\operatorname{Sr}(\%)$

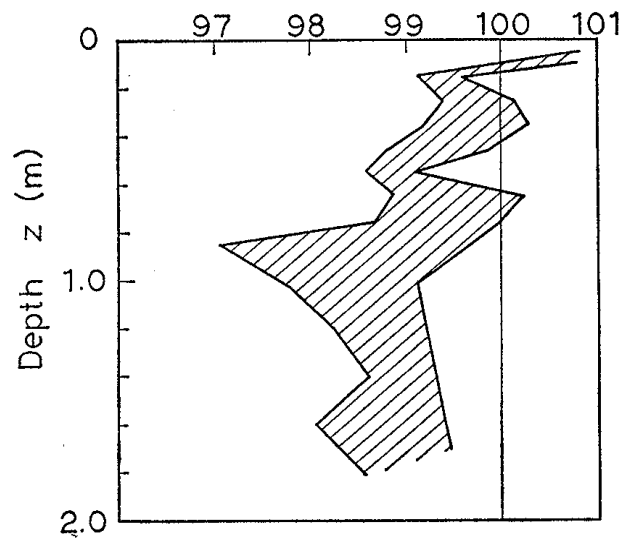

Fig. 14. Distribution of degree of saturation

\section{Degree of Saturation}

Fig. 14 denotes the degree of saturation measured after the tests by cutting out the deposits in each cell with a thin plate. Before cutting the cell, the water was drained from the bottom down to the surface level of the deposit and the water in the deposit in the uppermost cell was drawn by a spoon. Then, the unsaturated state of the deposit was cut out by the cell. The weight of the deposit

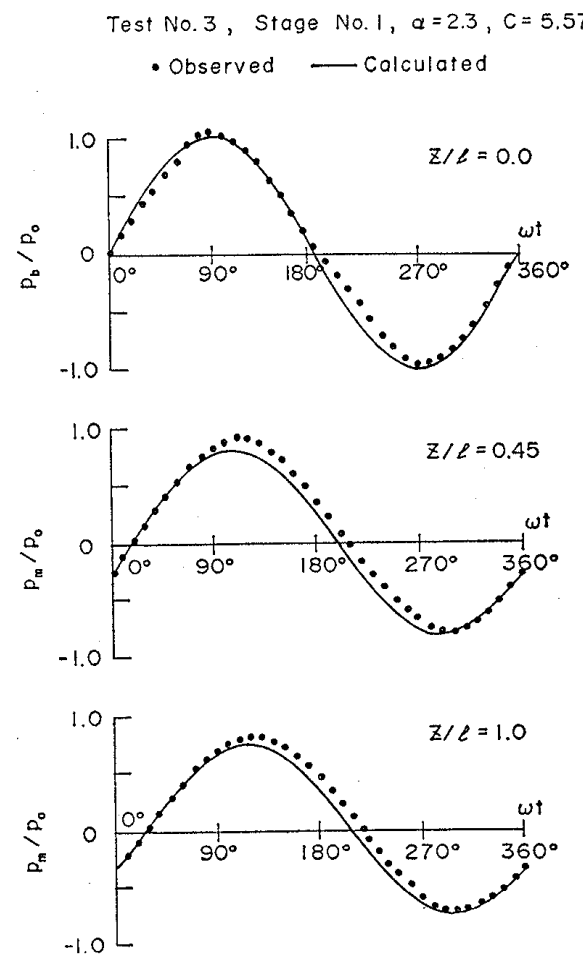

(a) taken out of the cell was measured together with the water drawn beforehand by the spoon. The degree of saturation thus measured lies between $97 \%$ and $101 \%$. Morethan $100 \%$ of the $S_{r}$ around the surface of the deposit may be attributed to the technical reason that

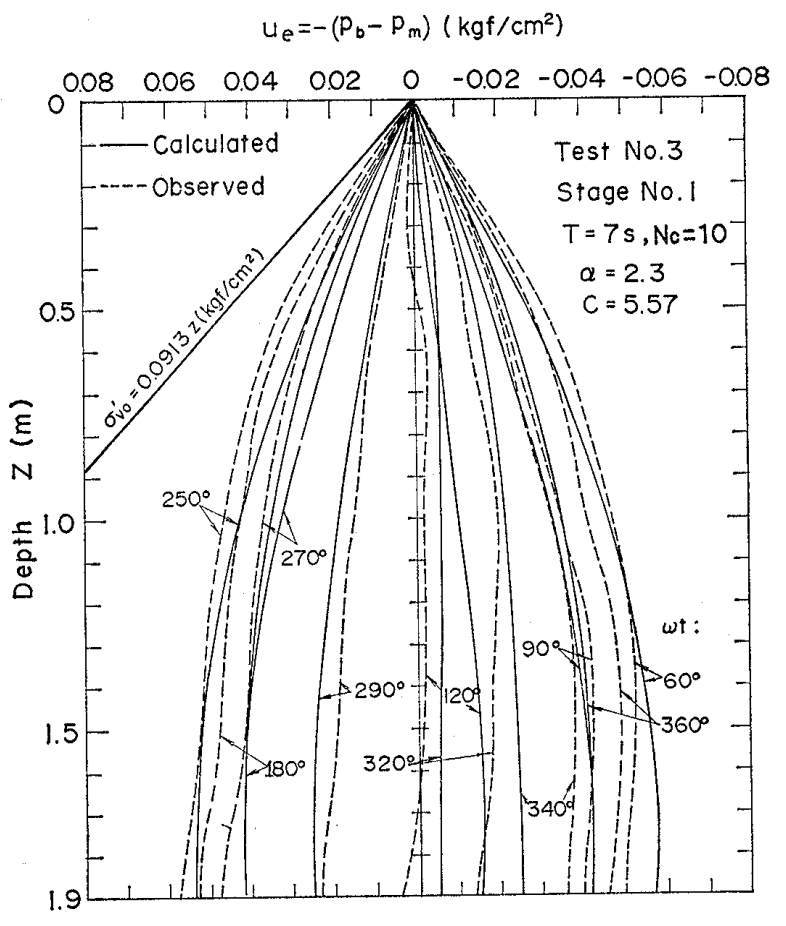

(b)

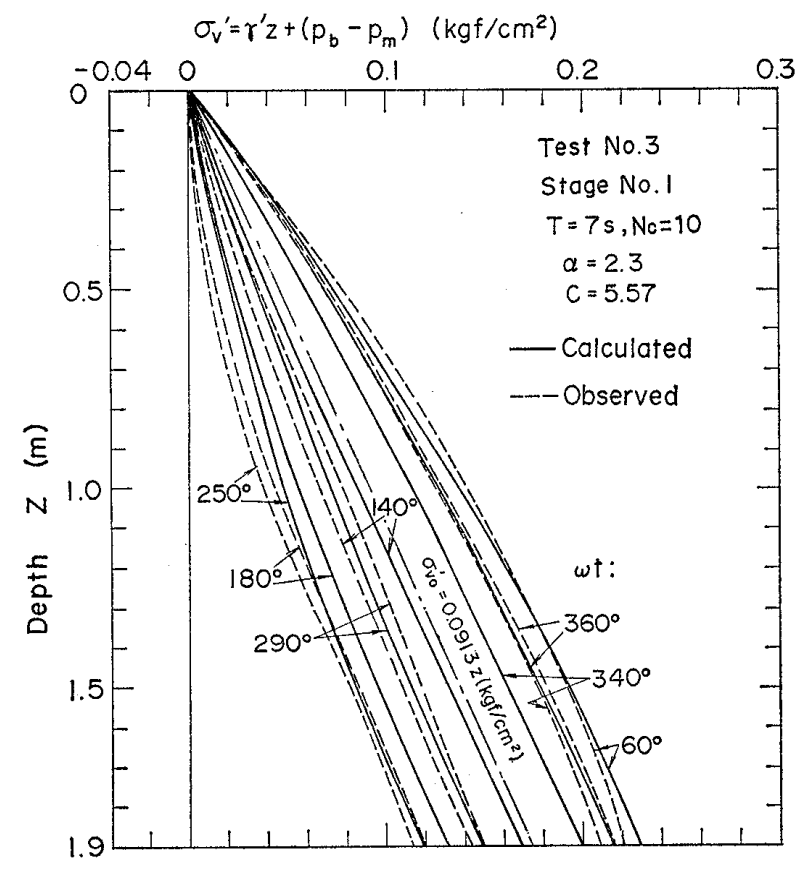

(c)

Fig. 15. Comparisons between theory and measurements $\left(1 \mathrm{kgf} / \mathrm{cm}^{2}=98 \mathrm{kN} / \mathrm{m}^{2}\right)$ (a) Pressure ratio, (b) Excess pore pressure, (c) Vertical effective stress 
the water above the deposit in the uppermost cell couldn't be separated from the pore water in the deposit in the process of the drainage because of the slight niclination of the deposit surface after the wave loading.

\section{DISCUSSIONS}

\section{Oscillatory Pore Pressure and Liquefaction}

The observed oscillatory pore pressures are presented in Fig. 15, together with the theoretical ones. The observed data are obtained from the tests performed under the double amplitude of the applied water pressure, $2 \bar{p}_{0}=$ $0.247 \mathrm{kgf} / \mathrm{cm}^{2}\left(24.2 \mathrm{kN} / \mathrm{m}^{2}\right)$, and the wave period, $T=7 \mathrm{~s}$. The thickness of the deposit is $1.90 \mathrm{~m}$.

Fig. 15 (a) shows the pressure ratios at the non-dimensional depths, $z / l=0.45$ and $z / l=$ 1.0. The damping and phase lag of the $p_{m}$ agaist the $p_{b}$ are clearly shown in Fig. 15. (a) As previously mentioned, these damping and phase lag lead to the excess pore pressures in the deposit. The oscillatory excess pore pressure, $u_{e}$, which is equivalent to the waveassociated vertical effective stress, $\left(p_{b}-p_{m}\right)$, is illustrated at the typical phases, $\omega t$, between $0^{\circ}$ to $360^{\circ}$ in Fig. 15 (b). It is quite interesting that the $u_{e}$ indicates not only the positive values but also the negative ones. The oscillation of the $u_{e}$ brings about the periodical changes of the vertical effective stresses as demonstrated in Fig. 15 (c).

In the theoretical analysis, the coefficient of drainage, $C=5.57$, is determined from Eq. (19) by using the $C_{v}, T$, and $l$. The coefficient of propagation, $\alpha=2.3$, is determined from Eq. (28) with the $S_{r}, p_{m g}$ and $n / m_{v}$. The sinusoidal form of the wave-associated bottom pressure, $p_{b}$, is given as the boundary condition to the surface of the deposit, $z=0$. It is found from Figs. 15 (a) to 15 (c) that the theoretically calculated results compare very well with the ob-served ones.

Referring to Fig. 15 (b), the $u_{e}$ does not exceed the initial vertical effective stresses, $\sigma^{\prime}{ }_{v 0}$, at all. This means that the liquefaction is not induced in the deposit. It is, however, noted that the vertical effective stresses vary periodically as shown in Fig. 15 (c). Espe-

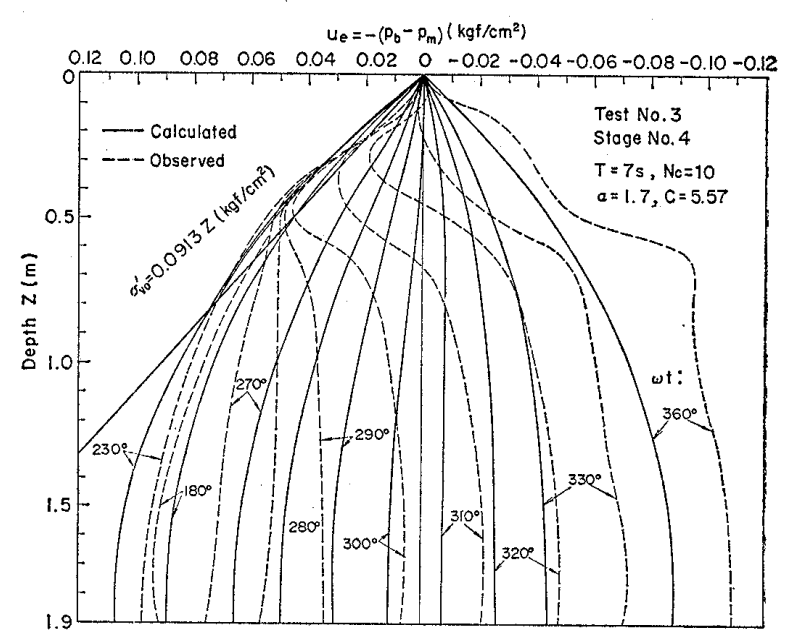

(a)

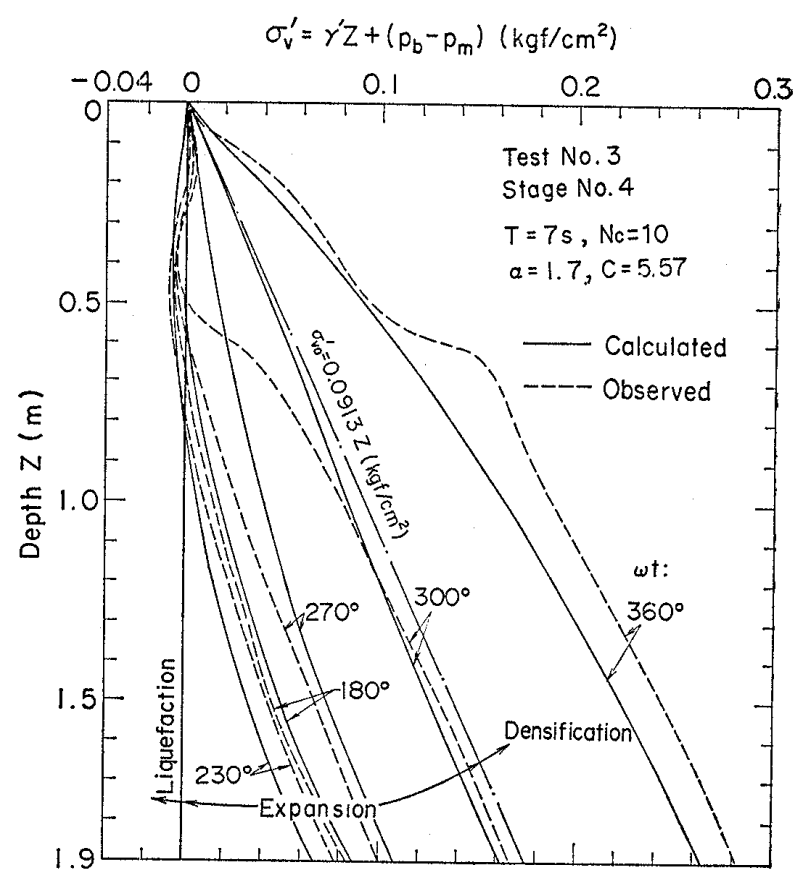

(b)

Fig. 16. Comparisons between theory and measurements $\left(1 \mathrm{kgf} / \mathrm{cm}^{2}=98 \mathrm{kN} / \mathrm{m}^{2}\right)$

(a) Excess pore pressure

(b) Vertical effective stress

cially, the vertical effective stresses become less than the initial vertical effective stresses, $\sigma^{\prime}{ }_{v 0}$, near under wave trough, say at the phase, $\omega t=250^{\circ}$. This fact is very important since the decrease of the vertical effective stress will lead to the reduction of the shear strength of sand deposits.

The excess pore pressures, $u_{e}$, observed for the $2 \bar{p}_{0}$ of $0.756 \mathrm{kgf} / \mathrm{cm}^{2}\left(74 \mathrm{kN} / \mathrm{m}^{2}\right)$ are pre- 
sented in Fig. 16 (a). In Fig. 16 (a), it is observed that the excess pore pressures exceed the initial vertical effective stresses, $\sigma^{\prime}{ }_{v 0}$, above some depths of the deposit. According to the liquefaction criterion expressed by Eq. (3), it is considered that the liquefaction is certainly brought about there. The liquefied depth is more clearly illustrated in Fig. 16 (b), in which the maximum depth of the liquefaction, $0.75 \mathrm{~m}$, is given at the phase of $230^{\circ}$.

The observed distributions of the oscillatory excess pore pressures in Fig. 16 (a) indicate some peculiar shapes above the depth of 0.75 $\mathrm{m}$ after the liquefaction occurs, and they are quite different from the analytical ones. The reason is considered that the suspended soil particles after liquefaction behave like a dynamic fluid and the assumptions introduced in the governing equation such as Darcy's law become impertinent. Post liquefaction phenomena should be treated with some other approaches.

It is demonstrated in Fig. 16 (b) that the water pressure oscillation induces the compressional stresses to possibly densify the deposit. Namely, the vertical effective stresses which exceed the initial vertical effective stresses, $\sigma^{\prime}{ }_{v 0}$, are observed at the phases beyond $300^{\circ}$. As already presented elsewhere ( $Z$ en and Yamazaki, 1990), the densification in sand deposits is attributed to these stresses repeatedly and alternately excited by waves.

\section{Seepage Force and Liquefaction}

The spacial differences of the oscillatory excess pore pressure in the seabed will exert seepage forces on the soil skeleton. As the increment of the vertical effective stress is represented by,

$$
\frac{\partial \sigma^{\prime} v}{\partial z}=j+\gamma^{\prime}
$$

the vertical effective stress is derived by integrating Eq. (33):

$$
\sigma^{\prime}{ }_{v}=\int_{0}^{z} j d z+\gamma^{\prime} z
$$

where $j$ : the seepage force and $\gamma^{\prime}$ : the submerged unit weight of deposits. Eq. (34) is equivalent to Eq. (1) when the $\sigma^{\prime} v_{0}$ is identi-

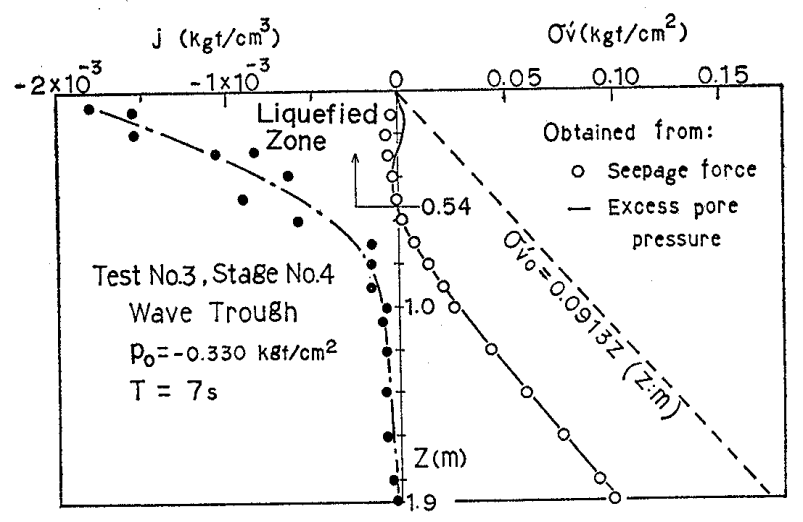

Fig. 17. Seepage force and vertical effective stress $\left(1 \mathrm{kgf} / \mathrm{cm}^{2}=98 \mathrm{kN} / \mathrm{m}^{2}\right)$

cal with $\gamma^{\prime} z$.

The seepage force, $j$, is derived from Eq. (1) by taking $\partial \sigma^{\prime}{ }_{v_{0}} / \partial z=\gamma^{\prime}$ and $\partial p_{b} / \partial z=0$ into account:

$$
j=-\frac{\partial p_{m}}{\partial z}
$$

Fig. 17 shows the seepage forces at the phase of $270^{\circ}$ calculated from the measured distribution of the $p_{m}$ by using Eq. (35). The negative value of the $j$ means the upward flow of pore water. It is found that the seepage force under wave trough becomes maximum at the surface of the deposit in this test case. The vertical effective stresses obtained from Eq. (34) and Eq. (1) are also illustrated respectively with the open circles and the solid curve in Fig. 17. Both the open circles and the solid curve show a good agreement with each other, indicating that the liquefaction, in other word a kind of quick sand, is caused at the depth shallower than $0.54 \mathrm{~m}$. Madsen (1974) concluded that the flow induced in a porous seabed by waves generally is of minor importance in the context of transport mechanics of soils. Carstens et al. (1976) demonstrated that the effects of pressure gradients, except the critical gradient, may be ignored in considering the scouring. As indicated in the previous section, however, the liquefaction will easily occur in real ocean environment. Once the liquefaction happens, the suspended state of soil particles will be transported as a fluid together with the bottom current. Furthermore, even if the liquefaction depth is 
limited to very near the surface of the seabed, the repeat of the liquefaction by a large number of cyclic waves may result in a critical scouring which causes a significant damages of offshore structures.

\section{Comparison between One and Two Dimen- sional Analyses}

The proposed theory is based on the assumption of one dimensional plane strain conditions. In order to examine the applicability of this assumption, one and two dimensional analyses are compared. The two dimensional elastic analysis presented by Okusa (1985) is used for the comparison. Since the liquefaction area is not clearly addressed in his analysis, the area which denotes the negative vertical effective stresses is compared with the liquefaction depth, $d_{l}$, calculated from the present analysis. The input data are listed in Table 3. The $\alpha$ in Table 3 is determined by assuming the elastic seabed. Under this assunption, the $(1 / \alpha)$ becomes equal to the B-value. Namely, the B-value of 0.5, which is used in Okusa's analysis, corresponds to the $\alpha$ of 2.0 . The results are illustrated in Fig. 18. It is clearly shown that both results compare well. Only the difference near the surface of the seabed may be attributted to the tensile strength of the soil expected in the two dimensional elastic analysis. Thus, it may be concluded that the assumption of one dimensional plane strain conditions of the seabed is reasonable when the wave length is large enough as shown in Table 3 and Fig. 18.

\section{CONCLUSIONS}

The response of the oscillatory pore pressure in the seabed associated with ocean wave propagation are theoretically and experimentally examined in the context of the wave-induced liquefaction. A governing equation of the oscillatory pore pressure is proposed and verified with the model tests. The following conclusions may be drawn from the study:

(1) The oscillatory pore pressure induced by ocean waves is generally expressed by Eq. (29), which is a function of the wave char-
Table 3. Input data

\begin{tabular}{ll|r}
\hline & & Loose sand \\
\hline Water depth & $h(\mathrm{~m})$ & 20 \\
Wave height & $H(=2 \eta)(\mathrm{m})$ & 5 \\
Wave period & $T(\mathrm{~s})$ & 15 \\
Wavelength & $L(\mathrm{~m})$ & 197 \\
Wave-associated bottom & $p_{0}\left(\mathrm{kgf} / \mathrm{cm}^{2}\right)$ & 0.207 \\
$\quad \begin{array}{l}\text { pressure at peak } \\
\text { Submerged unit weight of }\end{array}$ & $r^{\prime}\left(\mathrm{gf} / \mathrm{cm}^{3}\right)$ & 0.5 \\
$\quad$ deposits & $k(\mathrm{~m} / \mathrm{s})$ & 0.01 \\
Coefficient of permeability & & $9.0 \times 10^{-3}$ \\
Coefficient of volume & $m_{v}\left(\mathrm{~cm} 2 / \mathrm{kgf}^{2}\right)$ & 0.3 \\
Poisson's ratio & & 0.5 \\
B-value & & $4.16 \times 10^{-3}$ \\
Coefficient of drainage & $C$ & 2.0 \\
Coefficient of propagation & $\alpha$ &
\end{tabular}

1) $1 \mathrm{kgf} / \mathrm{cm}^{2}=98 \mathrm{kN} / \mathrm{m}^{2}$
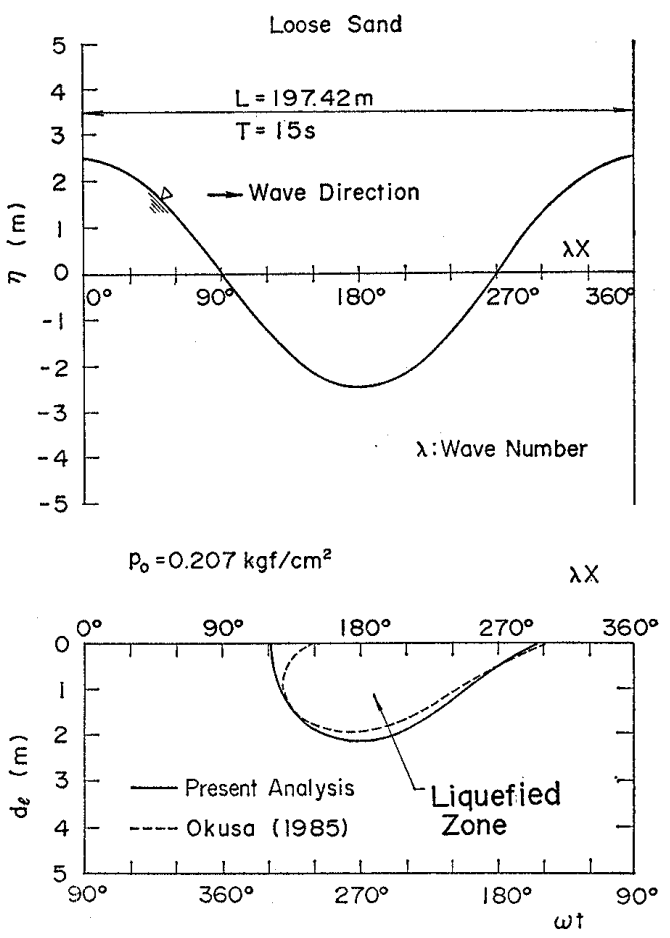

Fig. 18. Comparisons between one and two dimensional analyses $\left(1 \mathrm{kgf} / \mathrm{cm}^{2}=98 \mathrm{kN} / \mathrm{m}^{2}\right)$

acteristics, the properties of soils and pore water, and the geometrical factors of the seabed.

(2) Assuming the linear waves, the oscillatoly pore pressure in terms of the pressure ratio is represented by two non-dimensional parameters. These parameters are the coeffcient of drainage and the coefficient of propagation. Little effect of the number of waves on the oscillatory pore pressure is observed.

(3) The comparisons of the oscillatory pore 
pressure between the proposed theory and the measurement have shown a good agreement. The proposed governing equation is applicable to estimate the liquefaction potential in the porous seabed.

(4) The wave-induced liquefaction is caused by the upward seepage force repeatedly induced in the seabed, responding to the fluctuation of ocean waves.

(5) It is found that the oscillatory pore pressure may be analyzed under one dimensional plane strain conditions, when the wave length is large enough as treated herein.

\section{ACKNOWLEDGEMENTS}

The authors wish to express their sincere thanks to Mr. Atsushi Watanabe, JDC corporation, for his cooporation in performing the laboratory tests.

\section{NOTATIONS}

$$
\begin{aligned}
C & =\text { coefficient of drainage } \\
H & =\text { wave height } \\
h & =\text { water depth } \\
j & =\text { seepage force } \\
L & =\text { wave length } \\
l & =\text { thickness of permeable layer } \\
m_{w}= & \text { compressibility of pore water } \\
m_{w 0}= & \text { compressibility of pore water at fully saturat } \\
& \text { ed state } \\
N_{c}= & \text { number of waves } \\
n= & \text { porosity } \\
\bar{P}= & \text { pressure ratio }\left(=p_{m} / p_{0}\right) \\
p_{b}= & \text { wave-associated water pressure at the surface } \\
& \text { of seabed } \\
p_{m}= & \text { oscillatory pore pressure in seabed } \\
p_{m} g & =\text { oscillatory pore pressure in seabed in terms of } \\
& \text { absolute pressure } \\
p_{0}= & =\text { amplitude of } p_{b} \\
p_{0}= & \text { amplitude of applied dynamic pressure } \\
T & =\text { wave period } \\
\bar{T} & =\text { non-dimentional time }(=t / T) \\
\bar{U} & =\text { non-dimensional excess pore pressure }\left(=u_{e} / p_{0}\right) \\
u_{e} & =\text { excess pore pressure } \\
\bar{Z} & =\text { non-dimensional depth }(=z / l) \\
\alpha & =\text { coefficient of propagation } \\
\sigma^{\prime}{ }_{v}= & \text { vertical effective stress } \\
\sigma_{v 0} & =\text { vertical effective stress at calm } \\
\lambda= & \text { wave number }(=2 \pi / L) \\
&
\end{aligned}
$$

$$
\omega=\text { angular frequency }(=2 \pi / T)
$$

\section{REFERENCES}

1) Carstens, T., Brebner, A. and Kamphuis, J. W. (1976): "Seabed mobility under vertical pressure gradients", Proceedings of the International Conference on the Behaviour of Off-Shore Structures, Vol. 1, pp. 423-438.

2) Finn, W.D. L., Siddharthan, R. and Martin, G. R. (1983): "Response of seafloor to ocean waves", Journal of the Geotechnical Engineering Division, ASCE, Vol. 109, No. 4, pp. 556-572.

3) Inoue, R. (1975): "Propagation of pore water pressure in sand layer of high degree of saturation", Proceedings of the JSCE, Vol. 236, pp. 81-92 (in Japanese).

4) Liu, P.L.F., Timothy, P. and O'donnell (1979): "Wave induced forces on buried pipelines in permeable seabeds", Proceedings of the 4th Conference on Civil Engineering in the Oceans, pp. 111-121.

5) Madsen, O. S. (1974): "The stability of a sand bed under breaking waves", Proceedings of the 14th Coastal Engineering Conference, ASCE, Vol. 2, pp. 776-794.

6) Madsen, O. S. (1978): "Wave-induced pore pressures and effective stresses in a porous bed", Geotechnique, Vol. 28, No. 4, pp. 377-393.

7) May, C. and Foda, M. A. (1981): "Wave-induced stresses around a pipe laid on a pore-elastic sea bed", Geothecnique, Vol. 31, No. 4, pp. 509517.

8) Moshagen, H. and Tørum, A. (1975): "Wave induced pressures in permeable seabeds", Journal of the Waterways, Harbour and Coastal Engineering, ASCE, Vol. 101, No. 1, pp. 49-58.

9) Mynett, A. E. and Mei, C. C. (1982): "Waveinduced stresses in a saturated pore-elastic sea bed beneath a rectangular caisson", Geotechnique, Vol. 32, No. 3, pp. 235-247.

10) Nago, H. (1981): "Liquefaction of hightly saturated sand layer under oscillating water pressure", Memories of School of Engineering, Okayama University, Vol. 16, No. 1, pp. 91104.

11) Okusa, S. (1985): "Wave-induced stresses in unsaturated submarine sediment", Geotechnique, Vol. 35, No. 4, pp. 517-532.

12) Sleath, J. F. A. (1970): "Wave-induced pressures in beds of sand", Journal of the Hydraulics Division, ASCE, Vol. 96, No. 2, pp. 367378. 
13) Yamamoto, T. (1977): "Wave induced instability in seabed", proceedings of the ASCE Special Conference, Coastal Sediments '77, pp. 898-913.

14) Zen, K., Yamazaki, H. and Watanabe, A. (1987): "Wave-induced liquefaction and densification in seabed", Report of the Port and
Harbour Research Institute, Vol. 26, No. 4, pp. 125-1.80 (in Japanese).

15) Zen, K. and Yamazaki, H. (1990): "Mechanism of wave-induced liquefaction and densification in seabed", Soils and foundations, Vol. 30, No. 4, pp. 90-104. 